\title{
Ectopic thymus presenting as a right-side cervical mass in an infant
}

\section{Farbod Nasseri • Farzin Eftekhari}

Received: 7 August 2008 /Revised: 2 September 2008 /Accepted: 10 September 2008 / Published online: 7 October 2008

(C) Springer-Verlag 2008

A 3-cm, soft, nontender and mobile mass was detected in the right mandibular angle of a 7-week-old boy. A right parapharyngeal mass (Fig. 1, arrows) was discovered on MR imaging, isointense to muscle on T1-W images and hyperintense on $\mathrm{T} 2-\mathrm{W}$ and post-contrast images. It was isointense to thymus (Fig. 1, arrowheads) on all sequences. A core-needle biopsy showed thymic tissue.

Ectopic cervical thymus is a rare cause of a neck mass during infancy [1]. During its descent a remnant of thymus remains along the thymopharyngeal duct. It is often located between the superior vena cava, the brachiocephalic vessels and the aorta; rarely, it is within the posterior mediastinum [2]. This resultant "mass" can be mistaken for a pathologic process.

The differential diagnosis of a lateral cervical mass in an infant includes various congenital cysts, lymphatic malformation, branchial cleft anomalies, lymphadenopathy, and inflammatory or neoplastic lesions.

F. Nasseri $(\bowtie)$

Department of Radiology, Baylor College of Medicine,

One Baylor Plaza,

Houston, TX 77030, USA

e-mail: nasseri@bcm.tmc.edu

\section{F. Eftekhari}

Department of Radiology,

University of Texas M.D. Anderson Cancer Center,

Houston, TX, USA
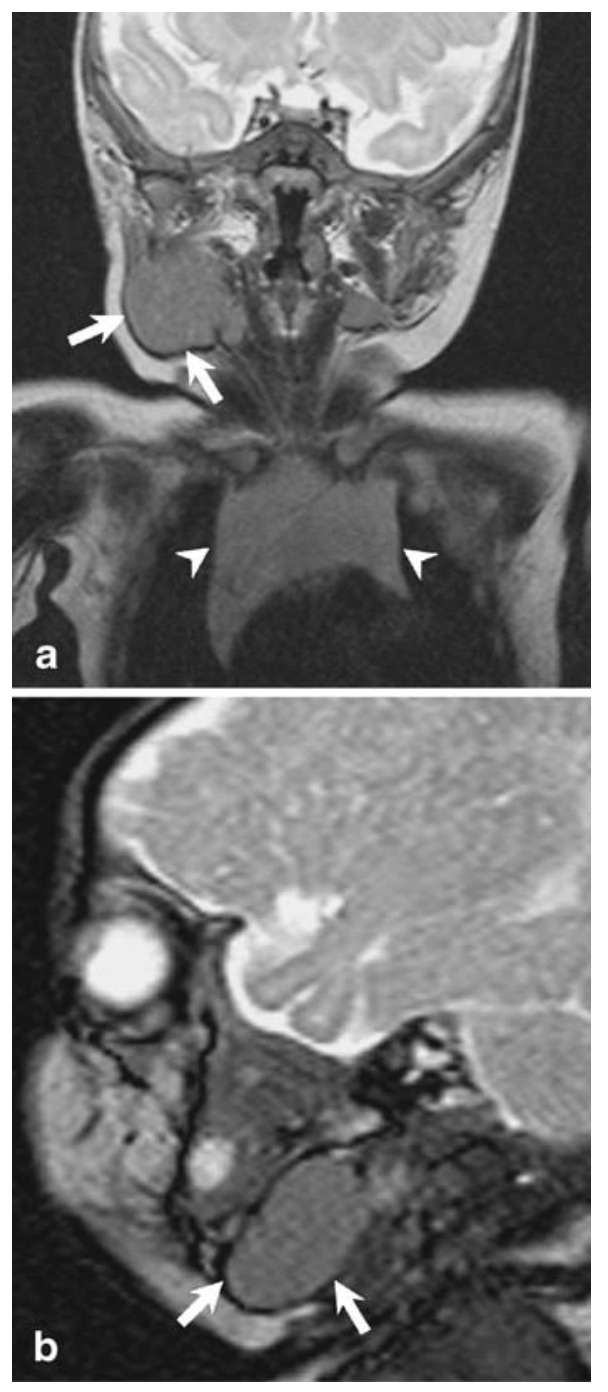

Fig. 1 MR T2-W images (a coronal, b sagittal) of ectopic accessory thymus

\section{References}

1. Loney DA, Bauman NM (1998) Ectopic cervical thymic masses in infants: a case report and review of the literature. Int $\mathrm{J}$ Pediatr Otorhinolaryngol 43:77-84

2. Slovis TL, Meza M, Kuhn P (1992) Aberrant thymus: MR assessment. Pediatr Radiol 22:490-492 